\title{
Charging undocumented migrant children for NHS healthcare: implications for child health
}

\author{
Neal James Russell, ${ }^{\oplus 1,2}$ Lisa Murphy, ${ }^{3}$ Laura Nellums, ${ }^{4}$ \\ Jonathan Broad ${ }_{1}^{5}$ Sarah Boutros, ${ }^{6}$ Nando Sigona, ${ }^{7}$ Delan Devakumar ${ }^{8}$
}

Recent changes to NHS charging regulations undermine child health and represent an unprecedented departure from the founding principles of the NHS. Justified by the narrative of 'health tourism', ${ }^{1}$ NHS 'overseas visitors' charging regulations now restrict access to NHS care for undocumented migrants living in the UK. This includes an estimated 600000 people, including 120000 children, of whom 65000 were born in the UK. ${ }^{2}$ Regulations include a charge of $150 \%$ of the NHS tariff for those unable to prove a regular status and sharing of personal data with the Home Office if debts are unpaid, effectively discouraging healthcare seeking with the threat of immigration enforcement. As such, the UK has abandoned universal health coverage, in conflict with the Sustainable Development Goals. ${ }^{3}$ We write this editorial in the context of growing concerns in the health community about the effects of these policies on child and public health, demonstrated most recently by a joint statement by the Royal College of Paediatrics and Child Health (RCPCH) and other medical colleges calling for suspension of this charging regime, ${ }^{4}$ as well as increasing recognition that 'migration and global health are defining issues of our time'.

\section{DEFINITION OF UNDOCUMENTED MIGRANT CHILDREN}

'Undocumented' (or 'irregular') refers to children lacking documentation proving a

\footnotetext{
'Paediatric Infectious Diseases Research Group, St George's University, University of London, London, UK ${ }^{2}$ Paediatric Registrar, London, UK

${ }^{3}$ Public Health England, London, UK ${ }^{4}$ Institute of Infection \& Immunity, St George's University, University of London, London, UK ${ }^{5}$ Paediatric ST2 and Academic Clinical Fellow, London, UK

${ }^{6}$ Paediatric Registrar, London, UK

${ }^{7}$ Department of Social Policy, Sociology and Criminology, University of Birmingham, Birmingham, UK ${ }^{8}$ Institute for Global Health, UCL, London, UK
}

Correspondence to Dr Neal James Russell, Paediatric Infectious Diseases Research Group, St George's University, University of London, London WC1E 7HU, UK; nrussell@sgul.ac.uk regular immigration status which, unless they are unaccompanied, is usually dependent on the status of, or applications made by, their parents. ${ }^{2}$ A child born in the UK to undocumented migrant parents may be considered an undocumented migrant, even without having ever left the UK. 'Undocumented' also includes unrecognised victims of trafficking and modern slavery, or children who have fled their countries of origin but are yet to seek-or have been refused-asylum.

\section{RECENT POLICIES REDUCING}

\section{HEALTHCARE ACCESS FOR CHILDREN}

Recent changes to healthcare access have been implemented as part of the government's 'hostile environment' policy for undocumented migrants living in the UK. The Immigration Act 2014 increased restrictions on entitlement to NHS care, alongside a $150 \%$ charging tariff, ${ }^{6}$ and in October 2017 legislation in England introduced mandatory upfront charging before treatment for those unable to prove their eligibility, and denial of care to those unable to pay. ${ }^{7}$ This applies to hospitals and a range of community services, including some NHS-commissioned charities. Treatment which is 'urgent or immediately necessary' can be provided, but may be charged retrospectively. ${ }^{7}$ Although A\&E and primary care are currently exempt, the government has also expressed an intention to introduce charging to these services. ${ }^{6}$ Some condition-specific exemptions exist ${ }^{7}$ (eg, some infectious diseases); however, there is limited awareness of these, or evidence they encourage healthcare engagement by undocumented migrants.

Importantly, in England the details of patients with unpaid NHS debts above $£ 500$ are referred to the Home Office after 2 months, which can lead to an immigration or asylum application being denied. ${ }^{8}$ Therefore families may face legitimate concerns that seeking care for their sick child may result in immigration enforcement such as detention, deportation and even family separation.
In addition, recent policies, such as an annual $£ 400$ NHS surcharge per child when making immigration applications, added to already prohibitively expensive application fees, are likely to increase destitution as well as present barriers to attaining or maintaining regular status. Children are thus at risk of losing 'entitlement' to NHS care depending on the immigration and financial status of their parents. This applies even to children born in the UK, who by law are only entitled to apply for citizenship after 10 years of residence, at an increasingly expensive price. This fluidity of migration status is often poorly understood in the context of public discourse categorising immigrants either as 'legal' or 'illegal', terms which should be strongly discouraged. The Windrush scandal highlighted publicly how changing residency rules, combined with reduced NHS entitlements, can also lead to misclassification of status and denial of NHS care.

\section{CONCERNS FOR CHILD HEALTH}

Studying the health of undocumented migrants is challenging as immigration status is rarely recorded, and fear of immigration enforcement may deter engagement in research and healthcare. Cases of children and pregnant women denied or deterred from care have been published by non-governmental organisations $^{9}$; however, the evidence base is limited, exacerbated by a lack of systematic awareness raising or collection of evidence of the implications of the charging regulations for child health.

Research that has been done on healthcare utilisation by child and adult undocumented migrants suggests lower use of health services than host populations, and in many cases worse health outcomes. ${ }^{10-12}$ Importantly, in the UK entitlement is complex $^{13}$ and poorly understood, and individuals have even been refused care they are entitled to, likely influenced by ID checking based on racial profiling, although most reported examples so far have been adults. Inappropriate refusal has occurred with hospital care, including exempt conditions, ${ }^{9}$ and primary care, with general practice surgeries frequently refusing registration despite official guidance that identification and proof of address are not required in primary care. ${ }^{14}$ Asylum seekers and refugees have also been wrongly charged despite being exempt from charging (refused asylum seekers are charged in England, except for a minority receiving specific Home Office support). 
Current regulations mean undocumented children may be less likely to see health professionals or be referred to paediatric services, with those referred potentially deterred from care. ${ }^{15} 16$ NHS trusts send letters to patients warning of ID checks, charging and immigration enforcement, and payment can be pursued before or between appointments, sometimes before a diagnosis is established. ${ }^{1516}$ Clinical teams may be entirely unaware of the potential influence of ID checks or charging on attendance and missed appointments. ${ }^{15}$

Restricting healthcare access is clearly detrimental for health outcomes, but also child safeguarding. NHS charging may exacerbate destitution and vulnerability of families while simultaneously creating barriers to identifying children at risk via healthcare contact, which is crucial in the context of fear of immigration enforcement discouraging reporting to police. ${ }^{315}$ Additionally, although children who are victims of trafficking or modern day slavery should be exempt, ${ }^{7}$ they may be less visible to services and remain unidentified, and are therefore at risk of being charged if seeking care. This could undermine identification and prevention of trafficking, modern day slavery and child abuse or sexual exploitation.

NHS charging may be particularly detrimental for newborns. ${ }^{17} 18$ As well as newborn care being chargeable, pregnant women confronted by charging are less likely to engage with maternity care, which although classed as immediately necessary, is still charged at $150 \%$ of the NHS tariff. Mothers face increasing destitution with unaffordable bills (eg, $£ 6000$ per delivery, but much higher should complications occur), and are still charged if the baby dies. ${ }^{12} 1516$ National statistics reveal disparities in maternal mortality and concerning increases in stillbirths and neonatal deaths among ethnic minority groups, but charging regulations have not been explored as an exacerbating factor. ${ }^{18}$

Undocumented adolescents also face great uncertainty over access to services and future employment, and anxiety about deportation. Not only can this impact mental health, ${ }^{2}$ but upfront charging may prevent access to care.

\section{CONCERNS FOR PUBLIC HEALTH}

Although primary care currently remains free, deterrence from early and preventive care due to charging and immigration concerns and barriers to GP registration are major public health concerns. Evidence exists of lower vaccination rates among migrant children than host populations, ${ }^{10} 19$ which is concerning given increasing vaccine preventable disease outbreaks across Europe. Additionally, although investigation and treatment of specific infectious diseases is exempt, ${ }^{7}$ families may be unaware of this and may not know a child's medical diagnosis before seeking care, potentially leading to delayed presentation, increased transmission and poorer health outcomes.

\section{A CALL TO ACTION}

NHS charging regulations undermine the government's stated commitments to child health and our obligations to children under the United Nations Convention on the Rights of the Child (Article 24), and contradict recommendations outlined in the UN Global Compact for Migration, signed by the UK in December $2018 .^{20}$ In contrast, in many comparable countries undocumented children and pregnant women are entitled to free healthcare. ${ }^{21}$

In the UK, health professionals must independently and systematically collect evidence on the harm of restricting children's access to healthcare. Internal governmental reviews relying on passive reporting without prior awareness raising among frontline clinicians cannot be relied on.

Child health professionals need to be aware of the regulations, including their power to define conditions as urgent, identify exemptions and challenge charging decisions. ${ }^{7}$ Ultimately, health professionals will be instrumental in advocating against the NHS charging system and its links to immigration enforcement, and for restoring universal health coverage and the right to health for children.

Twitter@NealJRussell @SarahB_Paeds@ lisamurphy107@nandosigona @DJDevakumar

Contributors NJR, LM, JB and SB conceived the idea and NJR wrote the first draft with significant contribution from LM. LM, LBN, DD and NS provided additional specialist input including content, additional referencing and editing, and SB and JB contributed edits to the final version. All authors approved the final version.

Funding LBN and DD are supported by funding from the Wellcome Trust (Grant Number . LBN and SH also are funded by the European Society for Clinical and Infectious Diseases (ESCMID) with research funding through the ESCMID for Infections in Travellers and Migrants (ESGITM). DD receives salary support from the National Institute for Health Research.

Disclaimer The views expressed are those of the authors and not necessarily those of the National Health Service, the National Institute for Health Research, the Department of Health or any other institution listed.

Competing interests None declared.

Patient consent Not required.
Provenance and peer review Not commissioned; externally peer reviewed.

(C) Author(s) (or their employer(s)) 2019. No commercial re-use. See rights and permissions. Published by BMJ.

$$
\text { Check for updates }
$$

To cite Russell NJ, Murphy L, Nellums L, et al. Arch Dis Child 2019;104:722-724.

Received 29 October 2018

Revised 9 January 2019

Accepted 27 January 2019

Published Online First 14 March 2019

Arch Dis Child 2019;104:722-724.

doi:10.1136/archdischild-2018-316474

\section{REFERENCES}

1 Steele S, Stuckler D, McKee M, et al. The Immigration Bill: extending charging regimes and scapegoating the vulnerable will pose risks to public health. J $R$ Soc Med 2014;107:132-3

2 Sigona N, Hughes V. No Way Out, No Way In. Irregular Migrant Children and Families in the UK. ESRC Centre on Migration, Policy and Society, 2012. https://www. compas.ox.ac.uk/wp-content/uploads/PR-2012Undocumented Migrant Children.pdf.

3 Onarheim KH, Melberg A, Meier BM, et al. Towards universal health coverage: including undocumented migrants. BMJ Glob Health 2018;3:e001031.

4 Royal College of Physicians. Royal colleges call for suspension of NHS overseas visitor charges pending review. 2018 https://www.rcplondon.ac.uk/news/ royal-colleges-call-suspension-nhs-overseas-visitorcharges-pending-review (accessed 20 Dec 2018).

5 Abubakar I, Aldridge RW, Devakumar D, et al. The UCL-Lancet Commission on Migration and Health: the health of a world on the move. The Lancet 2018:392:2606-54.

6 Lock DQ. Overseas visitors, asylum seekers and others: Who is entitled to access NHS services free of charges and who is required to pay charges for NHS services? Landmark Chambers, 2017. https://www. landmarkchambers.co.uk/wp-content/uploads/2018/ 06/Chapter-on-Who-can-access-NHS-services-andwho-is-required-to-pay-charges-for-NHS-services-0021.pdf

7 GOV.UK. Guidance on implementing the overseas visitor charging regulations. 2018. UK Government: Department of Health and Social Care. https://assets. publishing.service.gov.uk/government/uploads/system/ uploads/attachment_data/file/767905/guidanceon-implementing-the-overseas-visitor-chargingregulations.pdf (accessed 12 Aug 2018).

8 Doctors of the World. Response to the Independent Chief Inspector of Borders and Immigration's call for evidence: Home Office partnership working with other government departments. 2018. https:// www.doctorsoftheworld.org.uk/wp-content/ uploads/import-from-old-site/files/DOTW_ EvidenceForlCIBI_2018.pdf

9 Doctors of the World. Response to the Department of Health and Social Care formal review of The National Health Service (Charges to Overseas Visitors) (Amendment) Regulations 2017. 2018. See also Sigona and Hughes (2012). https://www.medact.org/ wp-content/uploads/2018/02/Medact-response-toDHSC-review-of-Amendments.pdf

10 Markkula N, Cabieses B, Lehti V, et al. Use of health services among international migrant children: a systematic review. Global Health 2018;14:52.

11 Winters M, Rechel B, de Jong $L$, et al. A systematic review on the use of healthcare services by 
undocumented migrants in Europe. BMC Health Serv Res 2018;18:30.

12 de Jonge A, Rijnders M, Agyemang C, et al. Limited midwifery care for undocumented women in the Netherlands. J Psychosom Obstet Gynaecol 2011;32:182-8.

13 Coram Children's Legal Centre (CLC). Access to secondary healthcare for migrant children, young people and families. 2018. https://www. childrenslegalcentre.com/resources/secondaryhealthcare/ (accessed 22 Dec 2018).

14 Patel A, Corbett J. Registration refused: a study on access to GP registration in England, Update 2017. 2017. https://www.doctorsoftheworld.org.uk/wpcontent/uploads/ import-from-old-site/files/Reg_ Refused_2017_final.pdf

15 Feldman R. What price safe motherhood? Charging for NHS maternity care in England and its impact on migrant women. 2018. https://www. maternityaction. org.uk/policy/publications/what-price-safemotherhood-charging-for-nhs-maternity-care-inengland-and-its-impact-on-migrant-women/

16 Doctors of the World. Deterrence, delay and distress: the impact of charging in NHS hospitals on migrants in vulnerable circumstances. 2017. https://www. doctorsoftheworld.org.uk/wp-content/uploads/ import-from-old-site/files/Research_brief_KCL_ upfront_charging_research_2310.pdf

17 MBRRACE-UK. Maternal, Newborn and Infant Clinical Outcome Review Programme. Perinatal Mortality Surveillance Report: UK Perinatal Deaths for Births from January to December 2016. 2018. https://www.npeu.ox.ac.uk/downloads/files/ mbrrace-uk/reports/MBRRACE-UK\%20Perinatal\% 20Surveillance $\% 20$ Full $\% 20$ Report $\% 20$ for $\%$ 202016\%20-\%20June\%202018.pdf

18 Shortall C, McMorran J, Taylor K, et al. Experiences of pregnant migrant women receiving ante/ peri and postnatal care in the UK: a longitudinal follow-up study of Doctors of the World's London Drop-In Clinic attendees. London: Doctors of the World, 2015. https://b.3cdn.net/droftheworld/ 08303864eb97b2d304_lam6brw4c.pdf

19 Williams GA, Bacci S, Shadwick R, et al. Measles among migrants in the European Union and the European Economic Area. Scand I Public Health 2016;44:6-13.

20 Devakumar D, Russell N, Murphy L, et al. Children and adolescents on the move: what does the Global Compact for Migration mean for their health? Lancet Child Adolesc Health 2019;3:64-6.

21 Stubbe Østergaard L, Norredam M, Mock-Munoz de Luna C, et al. Restricted health care entitlements for child migrants in Europe and Australia. Eur J Public Health 2017;27:869-73. 